\title{
Reflections on Digital Reading from a Cultural Perspective \\ Guohua Song
}

Jilin Engineering Normal University, Jilin 130052

1244534499@qq.com

Keywords: University students; Digital reading; Cultural reflections; Study on path

\begin{abstract}
Some reflections of university students on cultural connotation of digital reading were presented in the paper, aiming to enrich its core elements through an analysis of fundamental cultural connotations so as to support the structural optimization of educational system and cultural education on digital reading for continuous innovation of digital reading culture.
\end{abstract}

\section{Introduction}

Digital reading, a form of reading of digital texts or media information, is both a reading activity and cultural phenomenon. While the structure of digital publishing is being optimized and improved, its layout design has to meet human-oriented demands. This is particularly true of university students because digital reading for them is a means of mobile learning, social interaction and casual reading. However, its innovation and development has been restrained owing to the limitation of materials of traditional digital reading. Therefore, comprehensive reflections on reading culture in current development of the reading form are presented as below to arouse students' interest in digital reading and improve their academic performance, and offer effective supports to the innovation and optimization of higher education as a result.

\section{Status of Digital Reading of University Students}

Digital Reading Behaviors of University Students. In the environment of digital reading, students are able to read on a wide variety of vehicles like mobile phone, computer and electronic reader, etc. The convenience is favorable for the development of digital reading and the improvement of students' interest in reading.

Characteristics of Digital Reading of University Students. Digital reading has already become a tendency due to the development of information technology, but some students still prefer printed books from which they are able to acquire subjective mental experience that is limited in digital reading. It indicates that digital reading may have to overcome that limitation on the basis of cultural improvement. On the other hand, infiniteness of time and space of reading due to the development of information technology allows university students to read at any time and place. In other words, it is a form of "reading everywhere" which has revolutionized the reading culture.

Status of Digital Reading of University Students. In the first place, students often lack specific purposes in reading. Digital reading offers a great variety of materials in huge amounts concerning learning assistance, life-related information and entertainment and sports, etc. to them, but very few operators will provide academic papers when issues like copyright or costs are taken into consideration. As a result, students may only have to read through some news or reports on entertainment and will seldom read something with profound ideas or academic insights. Another deficiency of current digital reading is the lack of instructions, for studies have shown that many university students select materials at will in digital reading. It indicates that professional guidance is necessary for students in their reading and able to improve their interest in reading.

\section{Effects of Digital Reading of University Students upon Cultural Education}

Substitution of Digital Means to Traditional Reading. At present, university students can be found to read something probably including e-books or materials downloaded from a database like 
CNKI on portable readers whether in the dormitory and classroom or on public transportation, which suggests that fewer and fewer of them are interested in reading printed books anymore. In the context of information age, digital reading has turned out a universal and fundamental form of reading among them.

Transition of Closed Culture to Open Culture. Nowadays, culture is no longer developing in isolation but transmitted across traditional boundaries so that cultural resources can even be transmitted with unprecedented immediacy, precision and comprehensiveness. Take printed books for example, more and more of them which were not accessible have been open to the public due to the emergency of information highway. Besides, digital reading as a new reading form has broadened people's social interaction so that a reader is able to read what he likes anywhere, thus creating open space for reading. In addition, it increases students' contacts with culture, which will help to change their understanding about it and improve their sense of cultural identity.

Transition of Monopolized Culture to Shared Culture. Digital reading helps break down the barrier of reading, and reading no longer a minority privilege exclusive to the intellects. The fact suggests that digital reading plays a very important role in quality improvement of the whole people. For example, digital reading can help a university student lower his or her economic expenses on knowledge acquisition. Likewise, cultural resources will be transmitted more effectively to more people.

\section{Paths to the Optimization and Development of Digital Reading}

Fostering Students' Reading Habit. A university should be clearly aware of the development of digital reading, and try to integrate reading of recreational materials and classis literature by creating a good reading environment, e.g. establishing internet reading platforms like RSS push service, Weibo and mobile phone library, etc. where students are able to exchange information freely and enhance their effective understanding of what they read so as to arouse their own interest. Another point worthy to be noted is that a university student not only has to complete academic tasks but also promote their own comprehensive qualities. For such purposes, a university should be active in the promotion of reading activities. For instance, annual World Reading Day on April 23 is a good opportunity for universities to implant proper reading ideas in the students and demand relevant teachers to offer instructions to them based on an analysis of current status of their reading.

Promotion of Students' Capabilities in Literary Appreciation. In order to perfect digital reading platforms on the basis of traditional reading environment, a university should inspire students' interest in reading. Special courses like information retrieval are likely to be effective to help students master skills of access to and use of books on systematic integral platforms, so that they can obtain necessary information when they need. Meanwhile, a university library should recommend proper books to the students, integrate relevant information and optimize the information retrieval system of digital platforms when internet technology is being optimized the platforms keep developing. It will help students with mining of internet data and broaden their horizon. Conventional classroom is also an indispensable part in the construction of reading instruction courses for it will enable them to establish space for discussion in digital reading and investigate their problems actively. It will enhance students' interest in reading, promote their capabilities in literary appreciation, and help accomplish the final goal of digital reading cultural innovation.

Construction of Digital Reading Resource Center. As for digital reading, its core of development is the acquisition of reading resources. Hence, excessive expansion or loss of these resources should be avoided in the development of digital books. To solve the problem, a green and environment friendly digital resource storage system should be established to provide individualized and human-oriented reading methods for the students. In resource optimization, university libraries should establish an innovative resource management system on the basis of the development of digital resources including the following measures: 1) reinforcing digital resource introduction and updating information in time and swiftly; 2) reinforcing resource sharing of academic literature in digital reading resource database on an effective platform to convert students' 
papers to digital materials; 3) accumulating rich reading resources and introducing reading resources according to students' characteristics.

\section{Conclusion}

To sum up, digital reading as a wholly new reading form plays an important role in promoting students' cultural qualities. Therefore, university management should realize the factors which limit the development of digital libraries in guiding their reading activities. At the same time, they should try to enhance the utility ratio of digital resources, arouse students' interest in reading, transform their reading ideas through integration of other library resources. In this way, it is possible that students can improve their tastes both in reading and academic research. It will offer strong support to the development of digital reading, promote students' qualities and lay a solid foundation for the reinforcement of their comprehensive capabilities.

\section{References}

[1] Wang Xiaodan. An empirical study on digital media reading of university students[J]. Library Tribune, 2012, (06):131-135.

[2] Liu Na, Gao Chunyang, Qu Youyang, et al. Fostering of university students' digital reading capabilities[J]. Sci-Tech Information Development and Economy, 2014, (24) : 51-52.

[3] Liu Na, Gao Chunyang. A survey on university students' digital reading and a discussion on cultivation strategies - with universities in Liaoning Province as an example[J]. Hebei Sci-tech Library Journal, 2014, (06): :83-84+34.

[4] Ou Jihua, Zhou Wei, Hong Xuan, et al. A study on the relationship between motivation, self-efficacy and personalities[J]. Library Theory and Practice, 2016, (10) : 55-59.

[5] Teng Yushi. A survey on university students' digital reading tendencies from the perspective of the entire people - with Shanghai Theatre Academy as an example[J]. Digital Library Forum, 2015, (06):45-48.

[6] Ding Xuan, Kong Chao. An empirical study on influencing factors of university students' reading[J]. The Library Journal of Henan, 2016, (12): :124-126.

[7] Qian Ou, Li Xiangxiang. A study on the characteristics of students' mobile reading in comprehensive universities - from a perspective based on users' experience[J]. Library and Information Service, 2013(22): 92-98.

[8] Gao Chunling, LU Xiaojun, Zheng Yongbao. An analysis of differences of users' mobile reading based on individual characteristics - with teachers and students from Liaoning Normal University as an example[J]. Library and Information Service, 2013(9): 70-74.

[9] Research Group of National Reading Survey, Qu Mingying, Tian Fei. 10 conclusions of national reading survey in 2013[J]. Publishing Research, 2014(5): 9-12.

[10] Liu Bin, Li Gang, Guo Yirui, et al. A survey on status of university students' digital reading in Beijing[J]. Southeast Communication, 2013(4): 94-98. 